\title{
Tiroid Ultrasonografisi Sırasında Tespit Edilen Servikal Lipom: İki Olgu Sunumu*
}

\author{
Tiroid Ultrasonografisi Sirasında Tespit Edilen Servikal Lipom: Iki Olgu Sunumu
}

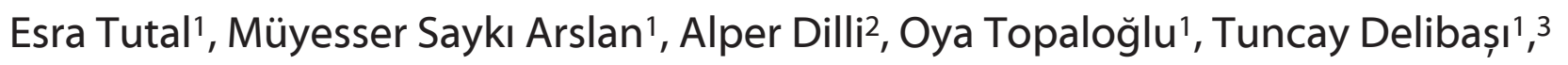

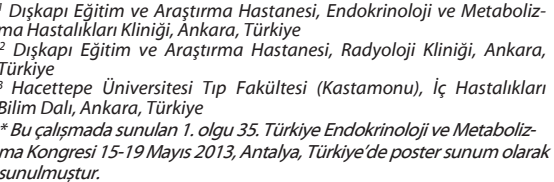

ma Kongresi 15-19 Mayıs 2013, Antalya Türkiye'de poster sumum otrak sunulmustur.

\begin{abstract}
Lipomlar vücudun herhangi bir yerinde gelișebilen en sık benign mezenkimal tümörlerdir. Servikal lipomlar yavaș büyüyen ağrısız kitle șeklinde kendilerini belli eden nadir tümörlerdir ve genellikle asemptomatiktirler. Bu olgu bildirisinde, tiroid ultrasonografisi sırasında tespit ettiğimiz iki servikal lipom olgusu radyolojik bulguları ile birlikte tartıșılmıștır.

Anahtar Sözcükler: lipom, boyun, ultrasonografi

Lipomas are the most common benign mesenchymal tumors which can arise in any part of the body. The cervical lipomas are rare tumours that may present as a painless mass with slow growth and are usually asymptomatic. In this case report, two cervical lipomas that identified during thyroid ultrasonography are discussed with radiologic findings.

Key Words: lipoma, neck, utrasonography
\end{abstract}

Lipomlar olgun adipositlerden köken alan, normalde yağ dokusunun bulunduğu herhangi bir lokalizasyonda gelișebilen ve en sik görülen mezenkimal tümörlerdir. Beşinci ve altınc1 dekatta daha sık görülürler. Çoğunluğu benign olan bu tümörlerin yaklaşık $\% 13$ 'ü baş-boyun bölgesinde, en s1k olarak da posterior boyun bölgesinde yerleşirler (1). Genellikle subdermal yerleşmekle birlikte, subfasyal, parosteal, interosseöz, intermüsküler, intramüsküler ve nadiren de parotis bezi içerisinde bulunabilir (2). İntermüsküler ve intramüsküler yerleșimli olanlar infiltratif lipomlar olarak da adlandırılırlar. Lipomlar yavaş büyüyen tümörlerdir ve tipik olarak asemptomatiktirler. İntermüsküler infiltratif lipomlar muhtemelen intermüsküler fasyal septadan köken alır ve yalnızca çevre kas dokusuna infiltre olurlar. Derin boyun bölgesinde saptanan lipomlara oldukça nadir rastlanır ve bunlar siradan yüzeyel lipomlara göre daha büyük olduğu için tümör boyutuna bağlı belirtilerle kendini belli ederler (3). Tümörün lokalizasyonuna göre dispne, öksürük, palpitasyon gibi semptomlara yol açarlar. Bu çalışmada farklı nedenlerle yapılan boyun ultrasonografisi (US) sirasinda saptanan iki olgu sunulmuştur.

\section{OLGU 1}

Ötiroid multinoduler guatr tanıs ile takip edilmekte olan 51 yaşındaki bir kadın hastanın rutin kontrolü nedeni ile yapılan tiroid US'de, tiroid sağ lob posterior komşuluğunda, karotis arteri yukarı iten, tiroid kapsülünden sınırları net ayırt edilebilen hafif heterojen kas dokusuna göre ekojen yapıda, içerisinde ince ekojen bantların izlendiği, düzgün sınırlı, belirgin vaskülaritenin izlenmediği, yuvarlak yapıda lezyon saptand1 (Resim 1).

Fizik muayenede lezyon lokalizasyonunda cilt normaldi ve palpasyonda lezyon saptanmadi. Lezyonun karakterize edilmesi amacı ile yapılan boyun manyetik rezonans görüntülemede (MRG), tiroid bezi sağ lob posteriorundan sağ toraks apeksine dek uzanan tüm sekanslarda yağ ile izointens sinyal özelliğinde, yağ baskilı sekansta baskılanan yaklaş1k 86x50 mm boyutlarında, trakeayı sağ lateralden sola doğru hafif basılayan lipom ile uyumlu kitle saptandı (Resim 2). Tanı ve tedavi amaçlı lezyona yönelik cerrahi rezeksiyon planlandi. Lezyon çevre kas dokuya infiltre olduğu için parsi- 
yel rezeksiyon yapilabildi. Patolojik değerlendirilmesinde fibroadipöz doku şeklinde yorumlandi. Postoperatif birinci yılda rezidü lezyon daha küçük olarak izlendi (Resim 3,4).

\section{OLGU 2}

Opere tiroid papiller karsinomu nedeni ile takip edilmekte olan 53 yaşında kadın hastada rutin boyun US sıra- sinda sol submandibuler bölgede 18x28 mm boyutlarında kas dokusuna göre ekojen yapıda ve heterojen görünümde, renkli doppler ultrasonografisinde kanlanma izlenmeyen oval görünümlü lezyon saptandı (Resim 5). Metastatik lenfadenopati olasılığ1 da dikkate alınarak ileri tetkik planladi. Serum TSH düzeyi $150 \mathrm{mIU}$ ve tiroglobulin düzeyi $<0,2 \mathrm{ng} / \mathrm{ml}$ idi.
Boyun MRG' de tüm sekanslarinda yağ sinyal özelliklerinde aynı lokalizasyon ve boyutta lipom ile uyumlu lezyon gösterildi (Resim 6). Lezyonun görece küçük olması ve bası semptomu oluşturmaması nedeni ile cerrahi eksizyon düşünülmedi ve takibi planlandi.

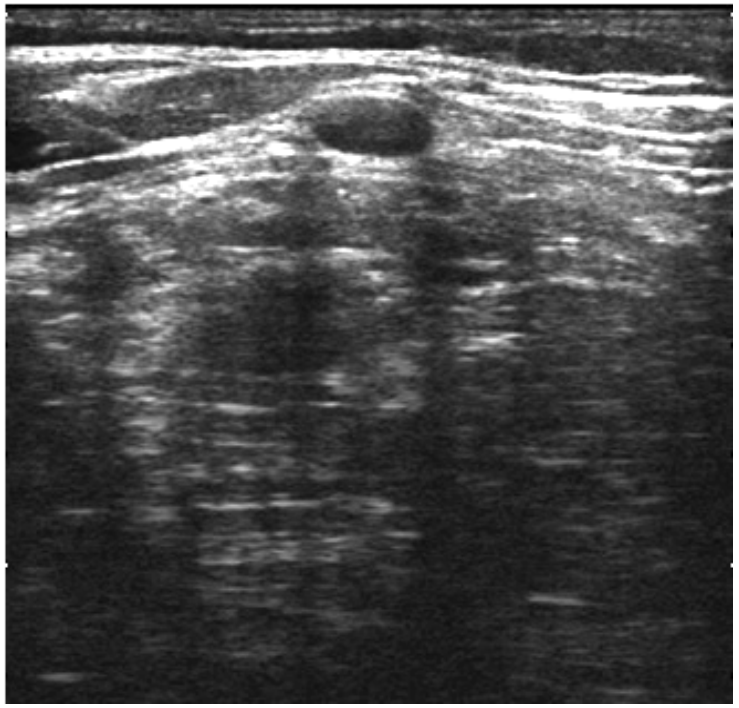

Şekil 1: Olgu 1'e ait lipomun ultrasonografide heterojen, kas dokusuna göre ekojen yapıdaki görünümü

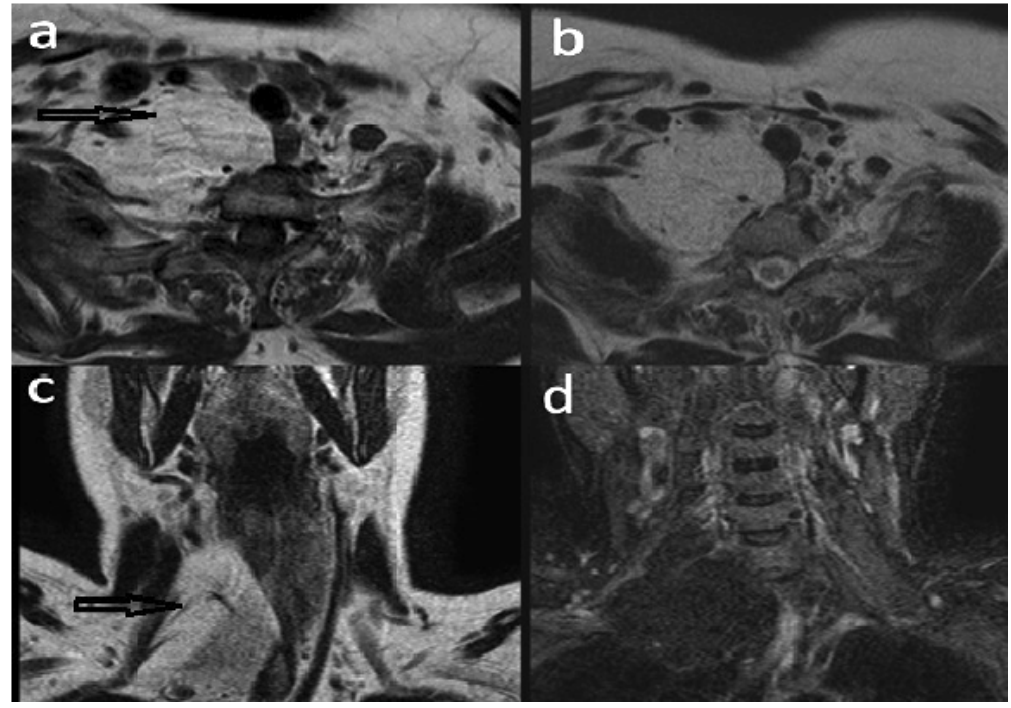

Şekil 2 a, b, c, d: Olgu 1'e ait Boyun MRG incelemesinde, boyun proksimalinde orta hat sağ lateralinde tiroid glandı sağ lobu inferiyor posterolateralinde anteriorunda juguler ven ve karotis arter ile posteriyorunda vertebra korpusu ile komşu, ayrıca boyun inferiyorunda sağ akciğer apeksine doğru uzanan mediyalinde trakea ve özofagusu lateralden baskılayan (a) aksiyel T1A (b) T2A ve koronal T2A sekanslarda hiperintens(c) ve koronal STIR(d) sekansta hipointens sinyal özelliğinde lipom (kırmızı oklar) izlenmektedir.

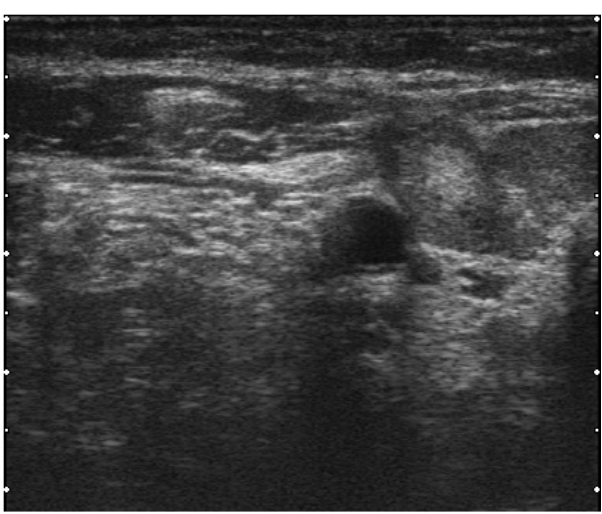

Şekil 3: Olgu 1'in postoperatif 1. yıldaki ultrasonografi görünümü heterojen hafif hipointens görünümdedir.

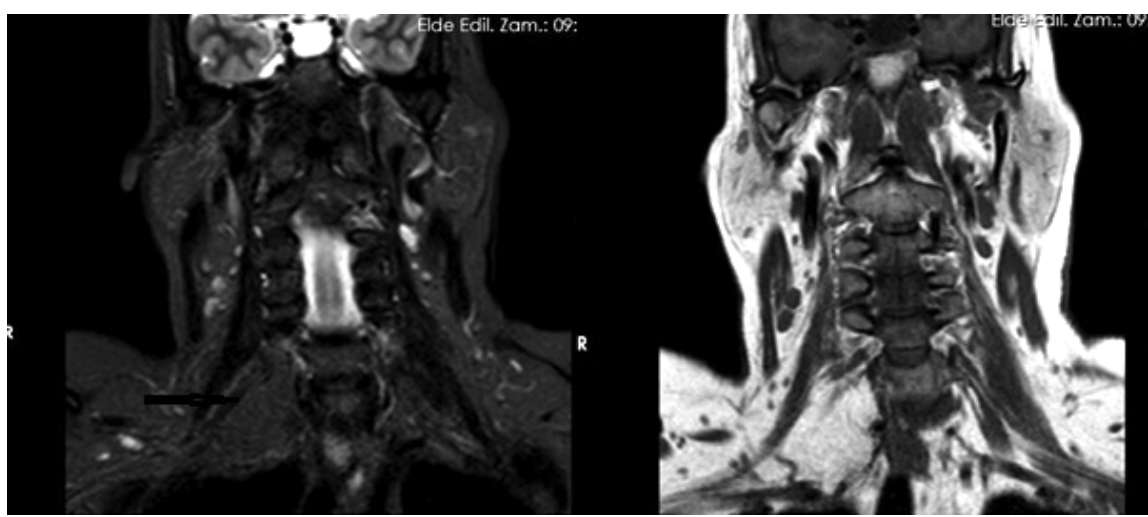

Şekil 4: 1. Olgunun postoperatif 1. yıl MR görüntüleri koronal STIR ve T1A görüntülerde hiperintens sinyal özelliklerinde (kırmızı ok) izlenmektedir. 


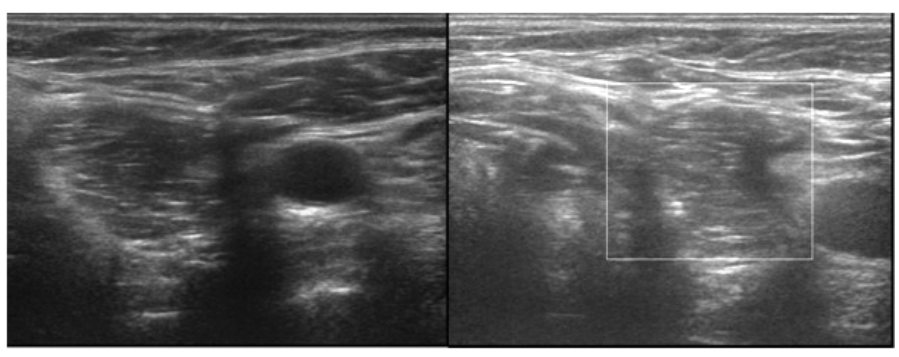

Şekil 5: Olgu 2'ye ait lezyonun ultrasonografik (a) görünümü kas dokusuna göre ekojen yapıda ve Doppler ultrasonografide (b) belirgin vaskülarite izlenmemektedir.

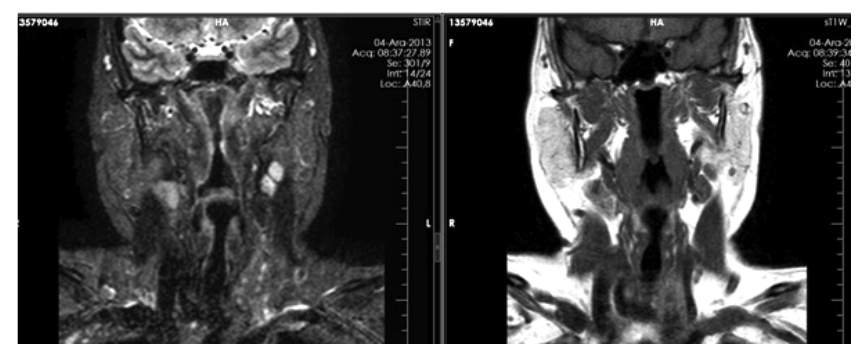

Şekil 6: Olgu 2'ye ait lezyonun MR görüntüleri: STIR sekansta (a) hipointens ve T1A görüntüde (b) hiperintens sinyal özelliğinde izlenmektedir (kırmızı ok).

\section{TARTIȘMA}

Lipom vücudun her yerinde rastlanabilen benign tümördür. Etyolojisi tam olarak bilinmemektedir. Sporadik veya nadiren Gardner sendromu, Madelung's hastalığ1 gibi bazı herediter hastalıklarla ilişkili olabilir. Endokrin, metabolik ve genetik hastalıklarla da ilișkili olabileceği düșünülmektedir. Bizim olgularımızda sistemik bir hastalık veya aile öyküsü mevcut değildi.

Boyun lipomu nadir tümörlerdendir ve yavaş büyüyen ağrisız kitle şeklinde kendisini gösterir. Lipomların \%80’i 5 cm'den küçüktür fakat nadiren dev boyutlara ulaşabilirler. Dev lipom terimi en az $10 \mathrm{~cm}$ genişlikte veya 1 kg'dan daha ağır olan olguları tanımlamak için kullanılır (4). Birinci olguda saptanan lipomun boyutu büyük olmasina rağmen hasta asemptomatik idi. Lipomların ayırıcı tanisinda lenfadenopati, brankial kleft kistleri, tükrük bezi tümörleri, karotid anevrizmas1, dermoid kistler, tiroglossal kist, ektopik tiroid nodülleri, vasküler leiomiyomlar yer almaktadır.

US baş-boyun bölgesinde yerleşen lipomların tanısında başlangıç görüntüleme yöntemidir. Tipik olarak US'de cilt yüzeyine paralel, komşu kas dokusuna göre hiperekoik, içerisinde lineer ekojen bantların izlendiği oval lezyonlardır. Fakat bazen farklı ekojenitelerde de olabileceği için daha ileri görün- tüle yöntemlerinin kullanılması gerekebilmektedir (2). Bir çalışmada lipomların renkli doppler US de vaskularite göstermediği raporlanmıştır (5). Bizim olgularımızda da lezyonlarda belirgin kanlanma izlenmedi.

Ayırıcı tanıda değerlendirilmesi gereken liposarkomlar da yağ dokusunun bulunduğu her yerde gelişebilirler ve yumuşak doku sarkomlarının yaklaşık \%35-45'ini oluştururlar. Bunların da $\% 2$ 'si baş-boyun yerleşimlidir (6). Derin intramüsküler yağ dokusundan gelişir ve lipoblastlardan oluşurlar. Tümörün nisbeten sert ve çevre dokuya fikse olduğu durumlarda liposarkomlardan şüphelenilmelidir. Atipik lipomatöz tümör/iyi diferansiye liposarkomlar liposarkom vakalarının \%4045'ini oluşturur ve en sık adipoz doku malign tümörüdür. S1klikla retroperitoneal bölgede yerleşseler de boyun bölgesi de sık yerleşim bölgelerinden biridir ${ }^{7}$. Iyi diferansiye liposarkomlar tipik olarak iyi sinırlı, multi-lobule ve heterojen ekoda görülürler. Yağa işaret eden hiperekoik odakların varlığ1 lipom ve liposarkom gibi yağ içeren lezyonları düşündürür. Ancak bu bulgu lipom ve liposarkomlar için spesifik ve sensitif değildir. US'nin liposarkomlar için tanısal yeterliliği bilgisayarlı tomografi/MRG ile karşılaşt1rıldığında düşüktür. İyi sınırlı liposarkomları lipomlardan ayırt etmek için power dopler US yapan bir çalışmada iyi sınırlı liposarkomların 2 kat daha hızlı akış gösterdiği saptanmıştır (8). Lipomların kesin tanısında MRG kullanılabilir. MRG'de T1 ağırlıklı görüntülerde hiperintens, T2 ağırlıklı görüntülerde ara sinyal özelliğinde, yağ baskılı görüntülerde baskılanan zayıf sinyal özeliğinde izlenir. Ayrıca MRG'de diğer görüntüleme yöntemleri ile saptanmayan, lipomları çevre adipoz dokudan ayıran "siyah-rim" ayırıcı tanıda önemlidir (1). Kesin tanı histopatolojik olarak konulabilir. Tam eksizyon sonrası bu tümörlerde metastaz ve rekürrens ihtimali çok düşük olduğu için radikal cerrahi bir işlem önerilmez (7).

Dev internal lipomlarin sarkomatoz transformasyon gösterebildiği bildirilmiştir. Dev lipomlarda maligniteyi ekarte edecek tanısal tetkiklerin (örneğin hikâye, fizik muayene, MRG ve gerekirse histopatolojik korelasyon) yapılması önerilmektedir (9).

Sonuç olarak tiroid US klinik pratikte tiroid ve paratiroid hastalıklarının tanı ve takibinde birçok endokrinolog tarafindan yaygin olarak uygulanmaktadır. Tiroid patolojileri araştırılırken, boyun bölgesinde karşılaşılabilecek farklı lezyonlar açısından dikkatli olunmalı ve lezyonları karakterize etmek için MRG kullanılmalıdır.. 


\section{KAYNAKLAR}

1. M.H. El-Monem, A.H. Gaafar, E.A. Magdy. Lipomas of the head and neck: presentation variability and diagnostic work-up. J Laryngol Otol. 2006;120:47-55.

2. F. Grecchi, I. Zollino, V. Candotto, et al. A case of lipoma of lateral anterior neck treated with surgical enucleation. Dent Res J (Isfahan). 2012;9:225-228.

3. G. Koç, C. Altay, N. Erdoğan, ve ark. Dev Servikal Lipoma, Servikal Bölgenin Nadir Benign Tümörü: İki Olgu Sunumu. Dokuz Eylül Üniversitesi Tip Fakültesi Dergisi 2012;26:207-210.
4. Y. Kimura, N. Ishikawa, K. Goutsu, et al. Lipoma in the deep lobe of the parotid gland: a case report. Auris Nasus Larynx 2002;29:391-393.

5. 5.Ahuja AT, King AD, Kew J, King W, Metrewedi C. Head and neck lipomas: sonographic appearances. AJNR Am J Neuroradiol 1998; 19:505-508.

6. O'Neill JP, Bilsky MH, Kraus D. Head and neck sarcomas: epidemiology, pathology, and management. Neurosurg Clin N Am. 2013 24:67-78.

7. Piperi E, Tosios KI, Nikitakis NG, et al. Well-differentiated liposarcoma/atypical lipomatous tumor of the oral cavity: report of three cases and review of the literature. Head Neck Pathol. 2012;6:354-363.

8. Futani H, Yamagiwa T, Yasojimat $H$, et al. Distinction between well-differentiated liposarcoma and intramuscular lipoma by power Doppler ultrasonography. Anticancer Res. 2003 23:1713-1718.

9. A. Terzioglu, D. Tuncali, A. Yuksel, et al. Giant lipomas: a series of 12 consecutive cases and a giant liposarcoma of the thigh. Dermatol Surg 2004;30:463-467. 